\title{
Uncovering Management Issues in Australian Classrooms Experienced by Non-English Speaking Background Teachers
}

\author{
Bushra Afzal* and Peter Charles Taylor \\ School of Education, Murdoch University, Western Australia, Australia
}

\begin{abstract}
Teachers from non-English-speaking background (NESB) constitute an important community of teachers in Australia, especially in Mathematics and Science discipline. During their journey of resuming teaching in Australian schools, they encounter a number of problems, including classroom management issues. Being an NESB teacher I have experienced acute classroom management problems, mostly related to students' behaviour and have been desperate to know the reality of the issue for other teachers. In this autoethnographic research, I developed a deeper understanding of these problems and possible solutions. I held a series of 'good conversations' with four NESB teachers from the Indian subcontinent. I represented the conversations in the form of narratives and subsequently subjected them to scholarly interpretive analysis. The study illustrates ways in which these NESB teachers faced severe student behaviour problems, which was a source of deep frustration for them. Major factors contributing towards these problems are cultural differences, language barriers and racism. I have learned from this study that NESB teachers, including myself, could improve class management skills by undertaking behaviour management courses prior to resuming teaching in a seemingly alien culture. Class management skills of NESB teachers can also improve with experience.
\end{abstract}

Keywords: NESB teachers, classroom management issues, auto/ ethnography, narrative, language 


\section{Introduction}

Non-English-speaking background (NESB) teachers are playing an important role in a culturally diverse country like Australia, and it is acknowledged that they provide a valuable resource to the teaching profession (Seah \& Bishop, 2001). NESB teachers face a range of problems more often than their native counterparts in their teaching journey. Class management issues come at the top of the list. Generally speaking class management issues are categorized as a main source of anxiety and distress both for novice and experienced teachers (Blankenship, 1988; Griffith, Steptoe, \& Cropley, 1999). According to Cains and Brown (1996), teachers believe that they run through an unreasonable amount of time to handle behaviour problems rather than teaching and academic tasks.

Having to be in a "culturally different other" situation adds to the problems of NESB teachers. McCluskey (2009) has highlighted issues faced by beginning or novice teachers who are from a non-English speaking background. Law (2010) has also investigated feelings of disempowerment and inefficacy experienced by Asian teachers, closely related to class management problems. But overall there is minimal attention given to the plight of teachers of non-English speaking background although a number of studies have been conducted globally and in Australian context with implications for meeting the needs of non-English speaking children in the classroom (for example, Capella-Santana, 2003; Evans \& Fisher, 2000). In this paper, being a NESB teacher myself I have endeavoured to have a deep insight into the class management issues while teaching in Australian classrooms.

When I was a high school student in a small town next to my village in Pakistan, my mother used to say with a passion in her voice "my daughter is going to be the headmistress of this school one day". Every time that irritated me, I really hated that wish of my beloved mother then, as becoming a teacher was not a wish of mine at all. I used to dream about being a scientist or something. When I finished my science degree and went back to my village, I was offered to teach science subjects at a local high school. I accepted the offer just to start off my practical life somehow. Without any experience or any professional qualification, I started my teaching career and I loved it. Very soon I discovered that I am a born teacher. Mainly, I taught biology and my students loved the way I explained concepts to them. My first graduates performed extremely well in their high school exams. After that I taught for nearly five years and got my teaching qualifications as well. I believe I became a true teacher in every sense of meeting the criteria described by Cruickshank, Jenkins and Metcalf (2003) as I was caring, 
supportive, concerned about the welfare of my students, knowledgeable about their subject matter, able to get along with parents... and genuinely excited about the work that I did.

I continued to thrive in my professional life. I even managed to become a deputy headmistress at a stage (my mother's dream came true - nearly!).

Then I migrated to Australia. I was desperate to start my teaching career again.

After a tiring journey of getting teacher accreditation which included achievement of the highest score in English exam, interview for suitability as a teacher, short training and then supervised teaching in an Australian school (it took me two and a half years to do all that), I finally became a teacher in Australia. But it was a shock to know that I was not the same successful teacher any more. Actually, at times I feel that teaching high school kids in Australia is a nightmare. Most of my energy goes to manage the students and their behaviour, rather than teaching the subject matter. Why is that? Is there anything wrong with the students or me? Why it is easy for my "Australian" colleagues to shut them up and it is so hard for me? Is there any role of my English language skills in my class management skills? Are these increased behaviour problems due to my brown skin (i.e., appearance)? Do other teachers with similar backgrounds to mine go through the same trauma? Do they feel the difficulty in class management the way I do? Are they happy and satisfied with the choice of profession they have made in Australia? Have they found any possible solutions?

Considering the above questions, I decided to talk to other NESB teachers as part of my postgraduate study. I asked my four participants and myself all these questions to help me become a good classroom manager again. Law (2010) has carried out a similar auto/ethnographic research to investigate the feelings of disempowerment and inefficacy experienced by Asian teachers as part of his doctoral study. But during my research I focused on NESB participants from similar backgrounds to mine, that is, teachers from the Indian subcontinent.

This study has empowered me to see more clearly where I am and where I can go from here. Moreover, by immersing myself in the study and involving other NESB teachers through 'inter/views' (Brinkmann \& Kvale, 2015), we have become more aware of the core issue that has for so long been torturing us in Australian schools. And by realising this pain we have become more conscious about and sensitive towards improving ourselves to survive in this seemingly different classroom culture. 


\section{Methodology}

I believe in the inter-subjective nature of social reality and that we come to know about social reality through making sense of and conversing about our lived experiences (Tobin, 1993). Thus, for this research I subscribed to the social constructivist epistemology of the interpretivist research paradigm (Taylor, Taylor, \& Luitel, 2012). Social constructivism holds that learning is a personal construction whose social viability is negotiated with others. For this inquiry, I opted for an interpretive research approach to generating, interpreting and representing my narrative constructions (Polkinghorne, 1988).

My chosen research method for developing a deep understanding of the phenomenon of NESB teachers' classroom management experiences (Bogdan \& Biklen, 1992; Straus, 1987) and co-constructing knowledge through selfconscious action (Kincheloe, 2002; Gibson, 1986) was the narrative auto/ ethnography. This is a well-known interpretivist research method that enables the researcher to excavate and reflect critically on the subjectivity and emotionality of her cultural experiences, both past and present, in conjunction with those of her fellow cultural insiders (Ellis, Adams, \& Bochner, 2011).

I conducted "semi-structured" interviews with four purposively selected NESB teachers, and subsequently reconstructed the interviews in the form of narratives or realist tales (Van Maanen, 1988). A series of one and a half hour indepth discussions were held during which I focused on enabling my participants to excavate their underlying beliefs and values regarding their experiences of students' classroom behaviour problems. Importantly, during this process I recounted my own experiences and reflections in order to motivate them to be open and honest in revealing their own (at times hurtful) experiences. This empathic and interactive approach to having a 'good conversation' is postmodern form of 'inter/viewing' (Brinkmann \& Kvale, 2015).

The interviews were audio-taped and pseudonyms were used to ensure confidentiality and anonymity of my participants. In order to optimise the quality of my inquiry I endeavoured to observe interpretivist research standards of trustworthiness, authenticity, verisimilitude and emergence throughout all phases of the study (Tayloret al., 2012).

In this paper, I present my own story as a NESB teacher interwoven with the stories of other NESB teachers struggling with classroom management problems. We (my participants and myself) sat together, shared our pain, discussed our 
hidden emotions and tried to find some solutions. While co-author of this article supervised the overall research activity and provided an ongoing support to write the paper.

\section{My Story as a NESB Teacher}

An overview of the key aspects of my teaching journey has been provided in the introduction of this paper. I have also outlined the problem of classroom management and my feelings regarding this issue. Below is one of the experiences that troubled me for a long time. This narrative is not only a reflection of students' bad behaviour but also lack of support and encouragement from the school board to the relief teachers.

I am never an early riser and waking up so early in a winter morning is the hardest thing ever. But what to do? I am a casual teacher and our "Casual Direct" may start calling us at 6:00 in the morning, to rush to replace someone who is sick or busy. So I have to sacrifice my sleep and my baby's as well. In return to this sacrifice, I will get approximately 295 dollars a day.

I get my crying nine months old ready along with myself, drop her off at her lovely career's place and follow the navigator to take me to some unknown destination.

This is my first day as casual teacher at this semi-selective public high school located in South-Western Sydney. I am told to take year 8 English class, though I was science trained.

In the third period, I enter year 8 with a movie in my hand given by the English head teacher. The students look at me and yell at each other to express their happiness that Mrs X is away. It's a very noisy class and they seem to be very interested in jumping around and yelling. I try to settle them down but cannot really find any luck to turn their volume down. Finally, the movie is on despite all the noise.

The movie is really of no use, if the intention was to keep them busy. It's a movie about ants and those quite "grown up" kids are calling it a "baby movie".

I am searching for the teacher's desk to find something more interesting and challenging. Here we go. I find some markers and an old lesson with instructions. I turn the TV off and write on the board 
74 B. Afzal \& P. C. Taylor

about the lesson I just found.

After a sentence or two, I realize I am using the permanent marker instead of an erasable one. Feeling embarrassed I try to erase the sentence. In doing so, I hear a laugh and then a boy saying to another, "She is a stupid Indian teacher." Blood rushes to my face but I keep trying to erase the marker ink. Now I hear the whisper of a girl, which was not quite a whisper and loud enough for the whole class to hear, "Look at her choice of clothing, she does not even know how to dress up."

Now I am angry, really angry and want to shout at them and tell them to shut up. But I just stop rubbing the board, turn around, and look at them with embarrassment, anger, disbelief and deep hurt. Nothing comes out of my mouth. I am speechless. I don't know how to express my mixed emotions to tell them off in a very aggressive way, so they don't dare to hurt anyone so bad in future. I am unable to find any proper and spontaneous words.

The little devils are busy again in whatever they are doing - boys jumping around, girls giggling and yelling at each other.

Finally, those everlasting 50 minutes are over. I approach the head teacher still traumatized with the experience I just had. She looks pretty busy, as all the head teachers do. I try to catch her attention and finally she looks away from her computer screen to find out who I am and what I want. I tell her after she recognises me what has just happened in the classroom. To all my complaints she really pays attention only to the permanent marker issue and "forgives me", saying "We all make that mistake, don't worry, someone will clean up the board."

"But how do you handle these students?" I really want to know. She is busy again, "That's just our low class", and starts typing on her keyboard, an indication for me to get out. So I do.

But am I ever going back to this school? No, even if they pay me $\$ 295$ a day and even that's just "their low class". And after those 50 minutes I can sympathise with all the casuals in Australian schools, especially "stupid Indian teachers", for the rest of my life.

The above experience of mine clearly narrates a number of factors. It 
underlines the life of a NESB teacher, especially when he/she is a casual/relief NESB teacher. Casual teachers play a key role in the smooth running of the school and it is a highly demanding form of teaching (Shilling, 1991). Still they can get very little in terms of respect from the students and support from their colleagues as evident from the behaviour of the head teacher in this narrative.

I agree with Shilling (1991) that instead of support from senior teachers they can receive thinly veiled warnings about their teaching competence, which provide very little direction or assistance. It's hard to be a casual but this could become a misery when students put casual teachers through the torment of disrespect.

Another important factor highlighted by this narrative is the racism that I faced from the students. McCluskey (2009) mentioned this factor in a recent study that skin colour/appearance could be one of the reasons for students' bad behaviour towards NESB teachers. Students criticised me for my dress and targeted my appearance/skin colour with very strident remarks of "stupid Indian teacher". It was acutely deleterious. I am still unable to understand how and why someone can do this kind of act to a teacher who has no intention to do anything wrong to them.

The third and most important issue described through this tale of mine was directly related to my English language skills. I was highly distraught at students' bad behaviour. I wanted to fully communicate my displeasure. But I could not even respond with a single word. The reason behind that was my difficulty in choosing spontaneous and suitable words to express my feelings and infuriation. In describing this type of situation, I accord with Lewis (2001) who says that it takes time to assimilate the kind of language that is appropriate for classroom use and the accepted way of interacting with students.

I explored all the factors of cultural differences, racism and language skills with other NESB teachers during my interviews.

\section{Raakhi's Story}

Raakhi had worked for seven years as a permanent science teacher in India. She has been teaching in Australia for the last six years on a casual basis, mostly in the same school. The school is a comprehensive public school located in South-Western Sydney, and has a mixed population of students from NESB and Anglo-Saxon backgrounds. She finds a significant difference in the classroom environments of India and Australia. She finds it conflicting how the teachers 
76 B. Afzal \& P. C. Taylor

perceive students' bad behaviour. Here is an illustration of her experience.

This is the third time I have asked her to take her hoodie off and she has ignored me again. Her way of ignoring is very interesting and challenging. She will stare at you while you are talking to her, shake her head when you are finished and then will go back to her activity which is generally throwing paper balls to other students or moving around from table to table.

I am familiar with the name of this year 7 girl, called Alicia, and I have heard some stories about her from other teachers too. But I never taught her before so I am not familiar with her real self. Today I have to spend two good hours with this class, including Alicia. And I am finding it a real challenge.

Now most of the kids are on task and I am in little peace, when Alicia suddenly rises up her chair, telling everybody very loudly that the class is really stuffy and we need to open the windows. Remember, this is the month of August (late winter) in Sydney and at least I can't see a reason for the classroom to be stuffy.

Alicia goes to the windows and starts opening them with a bang. A cold wind starts coming in. Students set their task aside; girls closer to the windows start screaming that it is cold. And it really is!

I tell Alicia to close the windows and settle down. She stares at me again with an intimidating smile, shakes her head and goes to her group of friends.

Now there are two groups in the class. Alicia and friends want to keep the windows open. Girls closer to the windows want to shut them. A fight across the tables has started and Alicia's group is more than capable to bully and win over the other poor girls.

I tell everyone to be quiet. I go to the windows myself and shut them. Alicia approaches in seconds and opens them again.

I put Alicia on lunch detention for her behaviour. She shakes her head again and tells her friends mocking me "Lunch detention, huh, these curry people...." They all laugh. It takes me a while to realise that they are making fun of me.

During lunchtime I go to the behaviour management co- 
coordinator and discuss Alicia's attitude. He is very sympathetic to me but his final comments are, "Do you know that this girl has ADHD (Attention Deficit Hyperactivity Disorder)?"

I never heard of ADHD during my seven years of teaching career in India. This is something I came across when I started working in Australian schools.

Until now I am wondering, are there really so many cases of $A D H D$ here or are we teachers just using ADHD as an excuse for our youth's bad behaviour?

Or maybe it is a phenomenon that "curry people" are unable to understand.

Raakhi's narrative is another tale of racism possibly faced by NESB teachers. She gets agitated at Alicia's behaviour and racist comments but she manages to display self-composure due to her long experience of teaching in Australia.

During the interview Raakhi exchanged her views in detail regarding differences in classroom culture of the two countries. This is depicted in her narrative when she says "I had never heard of ADHD during my seven years teaching career in India. This is something I came across when I started working in Australian schools." This sentence points to the cultural differences in the classrooms of India and Australia. It is hard to imagine that there was never a case of ADHD in Raakhi's teaching experiences in India in seven years. But it never occurred to Raakhi because classroom management was hardly a problem for her even in the presence of hidden cases of ADHD students.

\section{Zahoor's Story}

Zahoor has Pakistani background and is a very experienced teacher. $\mathrm{He}$ taught Science and Information Technology at the university level in Pakistan. After starting his career in Australia, he worked both as a casual and permanent science teacher in both the public and private sectors. In the first two years he worked in private schools as a part time employee. Then he took up casual teaching in public schools for two years. For the last six years he has been teaching science and physics in a comprehensive high school in an inner western suburb of Sydney. The majority of students in this school come from Middle Eastern background and some from the Indian sub-continent. He shares his classroom control and experience in this narrative very well. 
78 B. Afzal \& P. C. Taylor

I am waiting for the students of year 10 to settle down so I can start teaching them. They took longer than required as usual. But this does not make me frustrated as it used to be during the initial years of teaching in Australia. I hand them out the information about DNA and its structure. I think I am well prepared to teach this topic and will be able to achieve the outcomes. But let's see, what happens?

I ask Tony to read the information I have just given. He does not seem very interested but follows my instructions anyway.

I start explaining after Tony finishes. When I am in the middle of explanation, I hear the echo of my own words, someone mocking my Indian accent. This is Saad, one of the characters of year 10, interestingly having similar background like me (NESB). I stop for a while, look at him with a warning in my eyes. He just looks away and starts whistling instead of copying me.

After waiting for a few seconds, I start again and he repeats too. Anger starts developing inside me but I am still under control. But he doesn't seem to be in the mood of stopping this little play. The whole class is enjoying the situation. According to some unwritten pacts, they are all encouraging their fellow with their laughter. Anger keeps developing and finally I lose my self-control.

My 10 years of teaching experience in Australia has taught me the art to put my feet down in this situation and express whatever I am feeling.

I go in front of this young fellow, make an eye contact and tell him very firmly, loudly and angrily, "I know my English and my English accent is bad. But my English is definitely better than your parents'. That's why I am standing right here in front of you and they are not. You do not have a right to make fun of me and if you do, I will handle it very strictly."

The whole class is silent. Saad is trying to look away again to show that he does not really care. But it is written on his face that he does and he is experiencing the same hurt and embarrassment, which he has put me through. And that's exactly what I want and what I need to teach this challenging class.

Zahoor has told another story of hurt caused by possible racism for the 
NESB teachers leading to another interesting emergence. The student that mocked Zahoor was of similar background and the whole class, including Zahoor himself, was aware of it. Why was Saad doing this? We are not certain about that. Maybe he was just trying to be a "hero" as teenagers like to do. Or maybe he was hiding his own feelings of inferiority by targeting someone just like him. Anyway this is not the problem in question right now. But the attitude of Saad is meaningful in the context of Zahoor's interview "I have taught in both multicultural and Anglo Saxon dominated classrooms. I have often experienced more torturing and racism in multicultural classrooms."

Another indication by Zahoor's narrative and interview is again his experience and its relevance to classroom management issues. He knows exactly what and when he has to tell his students off. His English language skills, or poor accent, do not hinder him. He is fully confident to deal with a challenging class. We may not agree with the way he responded to his student and the choice of his sentences but we have to agree that he achieved the purpose of classroom control, which was required. And this seems to be the outcome of his long teaching experience.

\section{Sangeeta's Story}

Sangeeta is an Indian and thus English is her second language. She taught for one and a half year in Botswana and then moved to Australia. For the last seven years she has been a relief/ temporary teacher in the same public school of Campbell town, a Southwestern suburb of Sydney. The school population is mostly Anglo-Saxon and she likes to work there. Before starting to teach in Australia she completed a Master of Education in Australia and went through some courses regarding classroom management, which she found quite helpful later on. Here she tells the story of her class management.

It used to scare me a lot, when Nathan from year 9 would open his mouth in the middle of the lesson. Because whenever he opens his mouth, he passes some kind of sexually explicit remarks. I never had such experiences back in India and I used to feel very helpless in front of this student.

But years of experience and behaviour management courses have made me confident to respond to difficult students.

Today I am trying every possible strategy to avoid listening to Nathan's rude comments. I put him in the front row. I am giving him 
80 B. Afzal \& P. C. Taylor

attention every 10 minutes by praising his behaviour or asking $a$ question.

I teach this class Science and my topic is Force today. I define force, and then I explain how Pull and Push are examples of force.

And here goes Nathan "Miss, do you like push or pull?" He asks with a twinkle in his eyes. His fellows laugh loudly. They always do. They all work like a gang against poor teachers.

I can feel my cheeks burning and forget what I was talking about.

"Can you please stop making rude comments, Nathan?" I manage to be polite.

"What did I do Miss? I am just asking you a simple question. Do you like Push or Pull? I am asking you about force”, he insists.

"You know exactly what your question is about. And I do not want to discuss it any further", I flip my folder and try to dismiss the situation.

"Miss, you know what, your mind is dirty. You take the things wrong"; he puts all the blame upon me. He is very good at that.

"Nathan, do you remember your contract with me in the last term in front of your parents?" I remind him of his promise to do the right things and his signed contract.

"Yes miss, I do". He pretends to be very obedient but his cheeky smile is telling a different story.

I know he is not going to stop, but at least he can't scare me anymore, though he might upset me or disturb my lesson.

For this entire successful learning journey I am thankful to my colleagues, who taught me Classroom English Language.

Sangeeta's story is actually a success story. She has gradually learned and adapted to a different classroom culture. I must acknowledge that there is a lot for me to learn inform Sangeeta' story and she has added new dimensions to my inquiry.

While describing her experiences of teaching in two countries, she highlighted the possibility of classroom culture differences. She said, "I never 
had such experiences back in India and I used to feel very helpless in front of this student." When she was asked about the strategies of classroom management used in India and Botswana, her response was very innocent, "Strategies? I never had any class management issue in Botswana or in India."

Initially, she had a tough time as mentioned in this narrative. But her Education in Australia and training in behaviour management have helped her. She overcame her fear over time and today she is confident enough to deal with the very difficult situations.

In her interview, she also discussed the relationship of language with class management problems in detail. According to her, she also experienced the problem of a language barrier but she was a keen observer. She observed the way her colleagues communicated and responded to their students, and she followed them. She is still not as fluent as a native speaker in communication but her language skills are good enough to deal with the "gang of students".

\section{Samya's Story}

Samya is another Pakistani-based teacher working as a relief teacher in public schools of the Western suburbs of Sydney. Most of these schools have a high percentage of the student population from NESB background. She found it really hard to teach in Australia. She went through tremendous stress during her initial years of teaching. This is her seventh year of teaching and she is still not happy about being a teacher. This narrative explains very beautifully, why this is the case.

Today I am called to replace someone for the mainstream classes rather than Intensive English Centre (IEC) in this school. I have started casual teaching last year and am still struggling to cope with the cultural differences. I am not very confident, how to respond to students'bad behaviour. Actually at times, it scares me a lot. And I feel I am a failure as a high school teacher. Those bad behaving teenagers intimidate me very easily.

The class I just entered is multicultural, noisy, bouncy and very unsettled. I can recognize a few students whom I taught in IEC last year.

The head teacher provides the lesson. I am trying hard to run the class and implement the lesson, handing them the work sheets, instructing them to be quiet and getting on task. Most of them are 
ignoring me and continuing their own activities.

Ahmad in the front row, an ex student of mine from IEC, is not co-operating at all. I can well remember that he was absolutely a different student in IEC last year - a new arrival from Iraq then; respectful, a bit shy and quiet. But today he is absolutely different. He is moving around, ignoring whatever I am instructing and contributing loudly to the class noise.

Considering him as the same old Ahmad, I approach him and ask him to settle down. He laughs at me with a dare in his eyes and keeps ignoring.

Frustration has started developing inside me. I am losing the control of the class and losing my weak confidence.

Ahmad's behaviour is becoming more and more intolerable. He has just ripped his sheet of work and now throwing it to another student in the other corner of the room while yelling something in Arabic. That absolutely blows my mind too. I shout at him without considering the words I use. Actually I can't find other words for the situation "Can you shut up?"

That tall and quite heavy teenager springs out of his chair, moves forward in a very aggressive way and yells. "Are you saying that to me, to me?"

Ifeel scared, intimidated and very nervous. It looks as if he is going to punch me in the face with his clenched fist. "No, I was talking to the whole class", I tell him immediately. The class laughs and he sits down again with a victory written on his face and expressed by his gestures.

My sense of failure deepens. My self-esteem lowers. I feel hatred for these insulting monsters.

That night I talk to my father who has been a teacher in Pakistan for nearly all his life. I tell him the whole story of today with tears mixed in my voice. He listens to me with surprise, and sympathy and finally comments, "So in Australia, teachers get paid for being insulted."

I don't want to, but I have to agree with my father. 
This sentimental story of Samya coincides with my own in many ways, with some new dimensions as well. She is going through the general torment experienced by nearly every casual teacher interviewed for this study. She is also going through the difficult process of accepting a seemingly different classroom culture and finding it really hard when she says, "I don't want to, but I have to agree with my father."

Samya's narrative also mentions a clear link between language skills and classroom management. She is very upset at the student's behaviour. She has lost her self-control. She wants to deal with the situation. She wants to tell the "devil" off. But she could not find the proper words.

Just like Zahoor, she also highlighted the issue of racism during her interview that it is mostly caused by students who are not "White"/ Anglo Saxon but NESB themselves. Again, it is beyond the scope of this paper so I would leave it to the future researchers to explore the "reality of racism and multiculturalism in classrooms".

\section{Reflections and Conclusions}

My study was constructivist and it aimed at finding the reality of classroom management issues for NESB teachers. My ultimate goal was to improve my own management skills and I believe at the end of this project I begun to understand the problem better along with solutions. It helped me in transition from an undesired state to a final desired state, which was my purpose in adopting constructivist standpoint (Kincheloe, 2002). This research also enabled me to immerse myself in the study as a researcher participant, as a questioner and as a change agent, at least for my own self.

What happens in the classroom is primarily reflective of the cultural values of the school and the teachers (Weinstein, Curran, \&Tomlinson-Clarke, 2003). During my interviews with the participants, nearly every one reflected passionately how "obedient and good learners" their students were backin India/Pakistan and how "rude" they find the students here in Australia. This is an indication of possible cultural differences that NESB teachers can face in their classrooms. As described by Weinstein et al. (2003), "effective classroom management requires knowledge of cultural backgrounds"(p. 269), a cultural barrier between students and teachers could be the most important factor affecting class management skills of these NESB teachers. Levy, Wubbles, Brekelmans, and Morganfields (1997) mentioned that class climate contributing to learning can be 
84 B. Afzal \& P. C. Taylor

influenced by the cultural origin of the teacher and students, since the way people communicate and the way they perceive communication is culturally influenced. Immigrant teachers (NESB teachers in this case) often experience difficulty applying their cultural knowledge (Adair, Tobin, \& Arzubiaga, 2012).

So the very first challenge for these NESB teachers seems to be to cope and survive in a different classroom environment. In their home countries (India/ Pakistan) the participant teachers were used to students' responses with a 'yes' to teachers' instructions. But in Australia, their experiences are not similar. In this study the students needed constant motivation and active control at all times, and these NESB teachers took time to get used to it.

Secondly, often language plays a crucial role in the act of teaching and learning and English is NESB teachers' second language. Although only those NESB teachers are able to enter the Australian education system who display highly developed English language skills, still they are not native speakers. I know from my own experience that before getting accredited, NESB teachers go through a very tough English assessment (e.g., professional English assessment for teachers or PEAT in New South Wales, Australia).

A teacher's management decision-making process becomes more complex when she or he does not speak the first language of students (Curran, 2013). McClusky (2009) researched that teachers who work using their second language in a society foreign to them take time to assimilate the kind of language that is appropriate for classroom use and the accepted way of interacting with students. When it comes to expressing their reactions to students' bad behaviour, language restriction might not allow NESB teachers to properly and fully express themselves, thus being hesitant and not in full control of the classroom situation (McCluskey, 2009). And students can take advantage of that. I have openly expressed this language barrier in my personal narrative. It is also evident from Samya's story.

Thirdly, racism came up as an emergent issue. Racism usually involves the idea that one's own race is superior and has the right to dominate, which promotes offensive or aggressive behaviour to members of another race (www.dictionary. com). I personally faced such kind of behaviour and my participants (Zahoor and Raakhi) indicated that too. Scholars have struggled to understand the apparent stubborn persistence of racial phenomenon (Harrison, 1995; Mullings, 2005), especially in the classrooms. Despite the rhetoric of a multicultural Australia and the implementation of multicultural education, the present structure of schools 
can make them resistant to change (David, 1993), and can result in increased cases of racism. Australian Laws prohibit any kind of racism and discrimination in Australian society, including schools, so these NESB teachers were more subjected to a covert type of racism. As David (1993) mentioned, apart from the overt, wounding type of racism, migrant teachers are subjected to racism of the everyday type, which denies them their dignity and makes professional advancement very difficult.

Racism may lower the self-esteem of the target and shatter the confidence, which can affect a teacher's ability to control theclass. Cartledge and Johnson (1996) suggested that teachers who are the most effective classroom managers are those who are confident in their abilities. NESB teachers participating in this study along with myself are no exception. Experiences of racism may have contributed to lower our self-esteem and confidence and made it harder to be good managers, as expressed by Samya. Lewis (2001) agreed that disruptive student behaviour not only impedes learning outcomes for students but also impacts negatively on teacher efficacy and wellbeing.

Hope emerges for me in this inquiry when a participant NESB teacher (Sangeeta) indicates improvement in her classroom management skills through retraining in Australia, particularly focusing on class management issues. This finding accords with Spooner-Lane, Tangen and Campbell (2007) who suggested that NESB teachers need to learn more about Australian school culture and teaching practices.

I also gained the understanding during this study that years of experience can make a significant difference for a NESB teacher, if he/she is strong enough to survive the initial years of teaching. Likewise, observational skills and collegial support can play an important role while gaining teaching experience. This is evident from the narratives of two experienced participants, Zahoor and Sangeeta. Spooner-Lane et al. (2007) have strongly recommended more guidelines for NESB teachers regarding classroom observation for practicum, case scenario and samples of typical teacher talks during training to enhance their teaching capabilities.

I set out to find the reality of class management issues with the help of a small group of participants. And in doing so, this study has opened new dimensions of the problem for me. As a NESB teacher I was aware of some of the factors affecting my behaviour management skills. But my participants have unfolded new realities for me. They have provided me with some other relevant 
86 B. Afzal \& P. C. Taylor

issues (such as adverse forms of racism in multicultural classrooms) as well as encouraged me with some solutions.

I am not teaching at the moment, but now I am equipped with the hope to apply the knowledge and strategies obtained through this inquiry whenever I resume teaching.

\section{References}

Adair, J., Tobin, J., \& Arzubiaga, A. (2012). The dilemma of cultural responsiveness and professionalization: Listening closer to immigrant teachers who teach children of recent immigrants. Teachers College Record, $114(12), 1-37$.

Blankenship, C. S. (1988). Structuring the classroom for success. Australasian Journal of Special Education, 12(2), 25-30.

Bogdan, R., \& Biklen, S. K. (1992). Qualitative research for education. Boston, MA: Allyn and Bacon.

Brinkmann, S., \& Kvale, S. (2015). Inter Views: Learning the craft of qualitative research interviewing (3rd ed.). Thousand Oaks, CA: Sage.

Capella-Santana, N. (2003). Voices of teacher candidates: Positive changes in multicultural attitudes and knowledge. The Journal of Educational Research, 96(3), 182-190.

Cains, R. A., \& Brown, C. R. (1996). Newly qualified teachers: A comparative analysis of the perceptions held by B.Ed. and PGCE-trained primary teachers of their training routes. Educational Psychology, 16, 257-270.

Cartledge, G., \& Johnson, C. T. (1996). Inclusive classrooms for students with emotional and behavioural disorders: Critical variables. Theory Into Practice, 35(1), 51-57.

Cruickshank, D. R., Jenkins, D. B., \& Metcalf, K. K. (2003). The act of teaching. New York, NY: McGraw-Hill.

Curran, M. E. (2013).Linguistic diversity and classroom management. Theory Into Practice, 42(4), 335-340.

David, P. N. (1993). Everyday racism and the experiences of migrant. Queensland, Australia: University of Queensland.

Ellis, C., Adams, T. E., \& Bochner, A. P. (2011). Autoethnography: An overview. 
Historical Social Research / Historische Sozialforschung, 36(4), 273-290.

Evans, H., \& Fisher, D. (2000). Cultural differences in students' perceptions of science teachers' interpersonal behaviour. Australian Science Teachers Journal, 46(2), 9-18.

Gibson, R. (1986). Critical theory and education. London, England: Hodder and Stoughton.

Griffith, J., Steptoe, A., \& Cropley, M. (1999). An investigation of coping strategies associated with job stress in teachers. British Journal of Educational Psychology, 69(4), 517-531.

Harrison, F. V. (1995). The persistent power of "race" in the cultural and political economy of racism. Annual Review of Anthropology, 24, 47-74.

Kincheloe, J. L. (2002). Teachers as researchers: Qualitative inquiry as a path to empowerment (2nd ed.). London, England: Routledge Falmer.

Law, G. K. H. (2010). Teacher empowerment: An interpretive study of the experience of Asian migrant teachers in Western Australia (Unpublished doctoral thesis). Curtin University, Australia.

Lewis, R. (2001). Classroom discipline and student responsibility: The students' view. Teaching and Teacher Education, 17(3), 307-319.

Levy, J., Wubbles, T., Brekelmans, M., \& Morganfields, B. (1997). Language and cultural factors in students' perceptions of teacher communication style. International Journal of Intercultural Relations, 21(1), 29-56

McCluskey, K. (2009). The bridge from teacher preparation to beginning teacher: Helping NESB beginning teachers enter a community of teaching practice. Albury, Australia: Australian Teacher Education Association.

Mullings, L. (2005). Interrogating racism: Toward an antiracist anthropology. Annual Review of Anthropology, 34, 667-693.

Polkinghorne, D. E. (1988). Narrative knowing and the human sciences. Albany, NY: State University of New York Press.

Seah, W. T., \& Bishop, A. J. (2001). Crossing cultural borders: The negotiation of value conflicts by migrant teachers of mathematics in Australia. Paper presented at the Annual Conference of the Australian Association for Research in Education, Fremantle, Australia. Retrieved from http://www.aare. edu.au/data/publications/2001/sea01394.pdf 
88 B. Afzal \& P. C. Taylor

Shilling, C. (1991). Supply teachers: Working on the margins - A review of literature. Educational Research, 33(1), 3-11.

Spooner-Lane, R., Tangen, D., \& Campbell, M. (2007). When your first year is your final year: Changing perceptions of practicum through NESB preservice teachers' eyes. Paper presented at the $10^{\text {th }}$ Pacific Rim First Year Higher Education Conference, 4-6 July 2007, Queensland University of Technology, Brisbane, Australia. Retrieved from http://fyhe.com.au/past papers/papers07/final_papers/pdfs/5b.pdf

Straus, A. (1987). Qualitative analysis for social scientists. Cambridge, England: Cambridge University Press.

Taylor, P. C. (1998). Constructivism: Value added. In B. J. Fraser \& K. G. Tobin (Eds.), International handbook of science education (Vol. 2, pp. 1111-1123). Dordrecht, Netherlands: Springer.

Taylor, P. C., Taylor, E., \& Luitel, B.C. (2012). Multi-paradigmatic transformative research as/for teacher education: An integral perspective. In B. J. Fraser, K. G. Tobin, \& C. J. McRobbie (Eds.), Second international handbook of science education (pp. 373-387). Dordrecht, the Netherlands: Springer.

Tobin, K. G. (Ed.). (1993). The practice of constructivism in science education. New York, NY: Routledge.

Van Maanen, J. (1988). Tales of the field: On writing ethnography. Chicago, IL: University of Chicago Press.

Weinstein, C., Curran, M., \& Tomlinson-Clarke, S. (2003). Culturally responsive classroom management: Awareness into action. Theory Into Practice, 42(4), 269-276. 